\title{
Predicting the outcome of acute stroke: a prognostic
}

\section{score}

\author{
CMC ALLEN
}

From the Department of Neurology, Guy's Hospital, London, UK

SUMMARY A prognostic score was derived from a prospective study of 148 consecutively admitted patients, aged less than 76 years, who survived the first 24 hours after an acute stroke. Multivariate analysis was used to compare the presenting clinical features of $137(93 \%)$ of these patients with their outcome after two months. Little change in the level of residual disability was detected in 128 of these patients after a further four months. The features which were found to predict functional dependence or death included older age, complete limb paralysis, depression of conscious level and the combination of hemiplegia and hemianopia with higher cerebral dysfunction. Hemiparesis uncomplicated by hemianopia or higher cerebral dysfunction predicted a return to functional independence. A discriminant function derived from this analysis can be used to calculate the likelihood of recovery to independent function for an individual patient following an acute stroke.

The management of patients with an acute stroke requires some assessment of the likelihood of recovery. This prognosis may affect both the choice of initial medical therapy and the planning of rehabilitative programmes. ${ }^{1}$

Recent reviews have detailed the clinical features which are of prognostic value after a stroke. ${ }^{23}$ In general these features reflect the site and size of the lesions responsible for the stroke and the general medical condition of the patient. ${ }^{2}$ Individual prognosis however is hampered by a lack of information as to the relative weight that should be put upon these variables when they are observed in different combinations. Some attempts have been made to assess the prognostic significance of combinations of clinical features. ${ }^{14}$ These studies have been made of selected groups of patients in rehabilitation units. The results therefore may not be applicable to general hospital stroke admissions.

This study set out to establish a simple bedside method of outcome prediction by observing a consecutive series of patients on admission and then prospectively assessing their degree of social independence two and six months after an acute stroke.

Address for reprint requests: Dr CMC Allen, Department of Neurology, Middlesex Hospital, Mortimer Street, London W1N 8AA, UK.

Received 7 June 1983 and in revised form 1 November 1983. Accepted 18 November 1983

\section{Patients and methods}

Definition an acute stroke was defined as a focal, nonconvulsive deficit of brain function of vascular origin which had occurred within two weeks of admission to the study and which persisted for more than 24 hours.

Patients all patients under the age of 76 years with a stroke of acute onset who survived the first 24 hours in the general wards of Guy's Hospital between September 1st 1979 and September 30th, 1981 were examined by the author. This examination occurred within a mean time of 3.5 days from the onset of the stroke (range 1 to 13 days). Patients referred from other hospitals for investigation of their stroke were not included.

In addition to taking a clinical history and making a physical examination, the author ascertained from the attending staff and the case records details of the patients' condition on admission. On admission blood was drawn for estimation of the peripheral white cell count (WCC) and packed cell volume (PCV). A standard 12 lead ECG and chest radiograph were also performed shortly after admission.

Follow-up assessments were attempted on all patients in a special clinic or in the patients' homes two and six months after the onset of the stroke.

One hundred and fifty six patients were seen shortly after admission. Nineteen were excluded from the subsequent analysis. Eight of these patients were found to have mass lesions, three declined initial examination and eight were lost to follow up at two months. Nine more patients could not be traced after six months. Therefore of 148 early surviving patients with stroke, the outcome was known in $137(93 \%)$ after two months and $128(86 \%)$ 
after six months.

Of the 137 patients followed up, $114(83 \%)$ gave addresses in south-east London (London postal codes SE1, SE16, SE17, SE15 and SE13). Other patients were living at the time of their stroke in south-west London (7), North London (4), south-east Kent (7), Surrey (3), Essex (1) and Sussex (1). The latter four counties are areas from which central London receives commuter traffic and Guy's Hospital is situated close to a major London rail terminus. The patients therefore were local residents and some commuters.

Outcome Measures at follow up the patients' overall level of functional recovery was assessed upon a four point scale in terms of the degree of independence that they had achieved in the activities of daily living (table 1). From this assessment the patients were classified into those with a good outcome (groups 1 and 2) and those with a poor outcome (Groups 3 and 4).

The ability to make simple transfers of position was enquired after at follow up. Table 2 shows how these assessments of mobility corresponded with the overall outcome rating.

Type of stroke the pathological type of the stroke was diagnosed by CT scanning in 125 patients, at necropsy in six and clinically by means of a diagnostic score ${ }^{5}$ in six patients.

Clinical data the clinical features sought in all patients are listed in tables 3 and 4 . The neurological features used to define the patients' presenting syndromes are defined in table 5. Table 6 shows how these neurological deficits combined to produce a spectrum of nine syndromes.

Statistical analysis was performed with the aid of the "Statistical Package for the Social Sciences" (SPSS) ${ }^{6}$ on a University of London CDC 6600 computer.

The significance of observed differences in the distribution of the individual variables between the two outcome groups was tested by the Chi-squared test (with Yates' correction) or Students $t$ test.

Multivariate analysis was performed using the stepwise discriminant function program of the SPSS. Only those variables which made a difference in the separation of the prognostic groups at a significance level of $p<0.001$ were retained in the prognostic score.

In discriminant function analysis all variables are first coded numerically. A discrete variable is coded $0 / 1$ according to the presence or absence of that variable. Continuous variables (for example, age) are coded in the units in which they were measured.

A discriminant coefficient is calculated for each variable which, after allowance for differences in units of measurement reflects that variable's value in separating the groups. Comparison of the discriminating value of variables can be made by comparing the size of their standardised discriminant coefficients (table 7). The arithmetic sign of the coefficient represents the direction in which it is of discriminating value. For each patient a linear function can be derived by

$$
f=(x 1 . y l)+(x 2 \cdot y 2)+\ldots(x n . y n)+\text { Constant }
$$

(where $\mathrm{x}=$ variable code, $\mathrm{y}=$ unstandardised coefficient)

Table 1 Distribution of patients in defined outcome groups

\begin{tabular}{|c|c|c|c|}
\hline Group & Definition & $\begin{array}{l}\text { Two } \\
n(\%)\end{array}$ & $\begin{array}{l}\text { Six Months } \\
n(\%)\end{array}$ \\
\hline 1 & \multirow{4}{*}{$\begin{array}{l}\text { Not disabled. May have residual symptoms but fully } \\
\text { independent in activities of daily living } \\
\text { Mildly disabled. Can walk without aid. Independent in } \\
\text { ADL with aids or social services. Could live alone } \\
\text { Moderately to severely disabled. Can not walk safely } \\
\text { without assistance. Dependent. Incapable of living alone } \\
\text { Dead }\end{array}$} & $61(45)$ & $63(49)$ \\
\hline 2 & & 26(19) & $17(13)$ \\
\hline $\begin{array}{l}3 \\
4\end{array}$ & & $\begin{array}{l}21(15) \\
29(21)\end{array}$ & $\begin{array}{l}16(13) \\
32(25)\end{array}$ \\
\hline & & $137(100)$ & $128(100)$ \\
\hline
\end{tabular}

"Good outcome" = Groups 1 and 2

"Poor outcome" = Groups 3 and 4

Table 2 Outcome group and the ability to transfer

\begin{tabular}{|c|c|c|c|c|}
\hline \multirow[t]{2}{*}{ Transfer } & & \multicolumn{3}{|c|}{ Outcome Group } \\
\hline & & 1 & 2 & 3 \\
\hline Bed & $\begin{array}{l}\text { Independent } \\
\text { Assistance of one person } \\
\text { Fully dependent }\end{array}$ & $\begin{array}{r}61 \\
0 \\
0\end{array}$ & $\begin{array}{r}26 \\
0 \\
0\end{array}$ & $\begin{array}{l}9 \\
7 \\
5\end{array}$ \\
\hline Chair & $\begin{array}{l}\text { Independent } \\
\text { Assistance of one person } \\
\text { Fully dependent }\end{array}$ & $\begin{array}{r}\mathbf{6 1} \\
0 \\
0\end{array}$ & $\begin{array}{r}26 \\
0 \\
0\end{array}$ & $\begin{array}{r}10 \\
6 \\
5\end{array}$ \\
\hline Stairs & $\begin{array}{l}\text { Independent } \\
\text { Assistance of one person } \\
\text { Fully dependent }\end{array}$ & $\begin{array}{r}61 \\
0 \\
0\end{array}$ & $\begin{array}{r}19 \\
7 \\
0\end{array}$ & $\begin{array}{r}5 \\
1 \\
5\end{array}$ \\
\hline Bath & $\begin{array}{l}\text { Independent } \\
\text { Assistance of one person } \\
\text { Fully dependent }\end{array}$ & $\begin{array}{r}\mathbf{6} \\
0 \\
0\end{array}$ & $\begin{array}{r}21 \\
5 \\
0\end{array}$ & $\begin{array}{r}15 \\
2 \\
8 \\
11\end{array}$ \\
\hline
\end{tabular}


Table 3 Clinical variables not correlated with outcome $(p>0.05)$

\begin{tabular}{|c|c|c|}
\hline & \multicolumn{2}{|l|}{ Outcome } \\
\hline & $\begin{array}{l}\text { Good } \\
87(64 \%)\end{array}$ & $\begin{array}{l}\text { Poor } \\
50(36 \%)\end{array}$ \\
\hline $\begin{array}{l}\text { Male sex * } \\
\text { Previous stroke or TIA } \\
\text { Angina } \\
\text { Claudication } \\
>2 \text { absent pulses in lower limbs } \\
\text { History of hypertension } \\
\text { Previous myocardial Infarct } \\
\text { Heart valve mumurs } \\
\text { Congestive cardiac failure } \\
\text { Ischaemic ECG changes } \\
\text { Cardiomegaly (ECG) } \\
\text { Cardiomegaly (CXR) } \\
\text { Atrial fibrillation (ECG) } \\
\text { History of diabetes } \\
\text { Bilateral Babinski sign } \\
\text { Admission diastolic BP (mm Hg) (mean } \pm \text { SEM) } \\
\text { Systolic BP after } 24 \text { hours } \\
\text { Diastolic BP after } 24 \text { hours } \\
\text { Packed cell volume (PCV) }\end{array}$ & $\begin{array}{r}54(69 \%) \\
25(57 \%) \\
13(68 \%) \\
17(65 \%) \\
22(61 \%) \\
35(67 \%) \\
16(64 \%) \\
13(81 \%) \\
10(59 \%) \\
41(61 \%) \\
13(62 \%) \\
25(61 \%) \\
19(54 \%) \\
8(57 \%) \\
15(48 \%) \\
94( \pm 1 \cdot 8) \\
146( \pm 3 \cdot 0) \\
88( \pm 1 \cdot 8) \\
44( \pm 0.4)\end{array}$ & $\begin{array}{r}24(31 \%) \\
19(43 \%) \\
6(32 \%) \\
9(35 \%) \\
14(39 \%) \\
17(33 \%) \\
9(36 \%) \\
3(19 \%) \\
7(41 \%) \\
26(39 \%) \\
8(38 \%) \\
16(39 \%) \\
16(46 \%) \\
6(43 \%) \\
16(52 \%) \\
88( \pm 3 \cdot 0) \\
152( \pm 4 \cdot 0) \\
89( \pm 3 \cdot 0) \\
43( \pm 0.4)\end{array}$ \\
\hline
\end{tabular}

$* 0.0 j<\mathrm{p}<0.1$

In the stepwise procedure employed by the SPSS program, each variable is added to the discriminant in turn, starting with the most discriminating variable. The change in the separation of the prognostic groups and its statistical significance is measured with the addition of each variable. This allows only the most discriminating variables to be retained.

For each patient the value of the discriminant function can be taken as an indication of the relative likelihood of membership of one or other prognostic group, despite the non-normative character of the function.7 The SPSS program derives for each patient the probabilities of group membership (6).

\section{Results}

CLINICAL FEATURES AND OUTCOME

Tables three, four and six show the distribution of the observed clinical variables and neurological syndromes between those patients who achieved functional independence and those who were dependent or dead after two months. The features which individually showed a significantly different distribution between the two groups $(p<0.05)$ (table 4$)$ were analysed by the discriminant function method. The first six variables to make a difference at $p<0.001$ to the separation of the prognostic groups are listed in table 7.

When the discriminant function was used to predict the outcome of the patients from whose data it was created, $89 \%$ were allocated to their correct outcome group (assuming a classification criterion of $50 \%$ probability of group membership). The prediction results are shown in table 8.

\section{MAJOR CHANGES IN OUTCOME BETWEEN TWO AND SIX MONTHS}

Two patients who had achieved independence in daily living by two months after their stroke died of recurrent stroke in the next four months. One 74year-old lady judged independent after two months

Table 4 Variables correlated with outcome $(p<0.05)$

\begin{tabular}{|c|c|c|}
\hline & \multicolumn{2}{|l|}{ Outcome } \\
\hline & $\begin{array}{l}\text { Good } \\
87(64 \%)\end{array}$ & $\begin{array}{l}\text { Poor } \\
50(36 \%)\end{array}$ \\
\hline $\begin{array}{l}\text { Loss of consciousness at onset } \\
\text { Progression of deficit after admission } \\
\text { Drowsy or comatose on admission } \\
\text { Drowsy or comatose after } 24 \text { hours } \\
\text { Conjugate gaze palsy } \\
\text { Complete limb paralysis } \\
\text { Intracerebral haemorrhage } \\
\text { Age (yrs) (mean } \pm \text { SEM) } \\
\text { Admission systolic BP (mm) } \\
\text { Peripheral WCC } \times 10^{\circ} / 1\end{array}$ & $\begin{array}{r}10(36 \%) \\
6(35 \%) \\
17(37 \%) \\
11(27 \%) \\
14(38 \%) \\
24(39 \%) \\
9(36 \%) \\
62 \cdot 4( \pm 1 \cdot 0) \\
162( \pm 3 \cdot 8) \\
8 \cdot 8( \pm 0 \cdot 3)\end{array}$ & $\begin{array}{l}18(64 \%) \\
11(65 \%) \\
29(63 \%) \\
30(73 \%) \\
23(62 \%) \\
37(61 \%) \\
16(64 \%) \\
67 \cdot 7( \pm 1 \cdot 0) \\
147( \pm 4 \cdot 8) \\
10.9( \pm 0 \cdot 5)\end{array}$ \\
\hline
\end{tabular}


Table 5 Definitions of Neurological deficits

\begin{tabular}{|c|c|}
\hline Motor hemideficit & $\begin{array}{l}\text { Hemiparesis, hemiplegia or } \\
\text { unilateral central facial weakness }\end{array}$ \\
\hline Simple sensory deficit & $\begin{array}{l}\text { Loss or subjective dimunition of } \\
\text { Pinorick and/or light touch sensation }\end{array}$ \\
\hline Hemianopia & Homonymous visual field deficit to \\
\hline Higher cerebral dysfunction & $\begin{array}{l}\text { Aphasia (word finding difficulty) and/ } \\
\text { or parietal deficit as defined by } \\
\text { sensory or visual inattention, } \\
\text { visuospatial neglect or joint position } \\
\text { sense loss. }\end{array}$ \\
\hline Brainstem deficit & $\begin{array}{l}\text { Presence of ataxia, vertigo, dysarthria } \\
\text { without aphasia, oculomotor palsy } \\
\text { (excepting conjugate gaze palsy). } \\
\text { With or without motor or simple } \\
\text { sensory hemideficit but without } \\
\text { higher cerebral dysfunction. }\end{array}$ \\
\hline
\end{tabular}

was by six months after her stroke in long term geriatric care.

Two patients who had not achieved functional independence after two months were judged independent when assessed four months later. One had been slow in rehabilitation because of an ankle injury sustained in a fall shortly after her stroke. The other late recovering patient had a substantial nondominant hemisphere infarction and suffered a period of severe depression during the initial phase of his recovery.

\section{DEATHS}

Twenty-nine patients died within the first two months from the onset of their stroke. Six died in the second 24 hours after the stroke, seven in the remaining five days of the first week, eight in the next three weeks and eight in the second month. The primary causes of death were certified as cerebrovascular accident (11), bronchopneumonia (12) and pulmonary embolism (6). The cause of death had been ascertained by necropsy in nine patients.

Table 6 Outcome by neurological syndromes

\begin{tabular}{llll}
\hline & $p$ & \multicolumn{2}{l}{ Outcome } \\
\cline { 2 - 4 } & & Good & Poor \\
\cline { 2 - 4 } & & $87(64 \%)$ & $50(36 \%)$ \\
\hline Uncomplicated hemiplegia & $<0.01$ & $25(87 \%)$ & $4(13 \%)$ \\
Lone HCD & $<0.05$ & 11 & 0 \\
HCD + Hemi + HHA & $<0.001$ & $6(17 \%)$ & $29(83 \%)$ \\
Lone HHA & NS* & 8 & 0 \\
Hemi + HHA & NS & 2 & 3 \\
Hemi + HCD & NS & $17(61 \%)$ & $11(39 \%)$ \\
HCD + HHA & NS & 7 & 1 \\
Brainstem & NS & 10 & 2 \\
Pure Sensory & - & 1 & 0 \\
\hline Uncomplicated hemiplegia = motor hemideficit with or without \\
simple sensory loss, no hemianopia, no higher cerebral dysfunction \\
Hemi = hemiparesis/hemiplegia & & \\
HHA = homonymous hemianopia & & \\
HCD = higher cerebral dysfunction & & \\
$*$ & &
\end{tabular}

Table 7 Prognostic score

\begin{tabular}{llr}
\hline $\begin{array}{l}\text { Clinical feature } \\
\text { or syndrome }\end{array}$ & $\begin{array}{l}\text { Standardised } \\
\text { coefficient }\end{array}$ & Score \\
\hline Complete limb paralysis* & -0.59469 & Constant +40 \\
HCD + Hemi + HHA $\dagger$ & -0.46938 & -12 \\
$\begin{array}{l}\text { Drowsy or comatose } \\
\text { (after 24 hours) }\end{array}$ & -0.44016 & -11 \\
$\begin{array}{l}\text { Age (years) } \\
\text { Loss of consciousness }\end{array}$ & -0.39524 & -10 \\
$\begin{array}{l}\text { (at onset of deficit) } \\
\text { Uncomplicated hemiparesis }\end{array}$ & $-0 \cdot 34554$ & $-($ Age $\times 0.4)$ \\
& +0.34371 & -9 \\
& & +8 \\
\hline *MRC Scale 0 or 1 & Total \\
\hline †Higher cerebral dysfunction + Hemiplegia + Hemianopia
\end{tabular}

\section{PROGNOSTIC SCORE}

To simplify the practical use of the discriminant function, the unstandardised coefficients and the constant were multiplied by 10 and rounded to the nearest decimal place. Table 7 shows the score that the presence of each feature contributes to the prognostic function. The patient's age should be multiplied by 0.4 and then this and the score for any other feature present added to or subtracted from the constant of +40 . If this total is then taken to the figure, where the discriminant function values for each patient in this series are related to the calculated probability of outcome, the approximate likelihood of recovery can be determined.

\section{Discussion}

The discriminant function derived in this study combines several of the clinical features and neurological syndromes, most of which had previously been recognised as important for prognosis ${ }^{23}$ and permits more confident prediction of outcome than hitherto available.

An unexpected finding amongst the individual features of prognostic significance was the relationship of the admission systolic blood pressure to patients' outcome. This was on average significantly higher in those patients who did well after their stroke compared with those who became dependent or died. This difference could not be explained by the inclusion in the poor outcome group those with excessively low pressures. On the other hand, after

Table 8 Prediction of outcome by discriminant function

\begin{tabular}{llcc}
\hline Actual outcome & $n$ & \multicolumn{2}{c}{ Predicted good Predicted poor } \\
\hline Good (Groups 1 and 2) & 87 & 80 & 7 \\
Poor (Groups 3 and 4) & 50 & 8 & 42 \\
\hline Overall predictive value $=$ & $=89 \%($ Chi-squared $=83.6, p<0.001)$
\end{tabular}




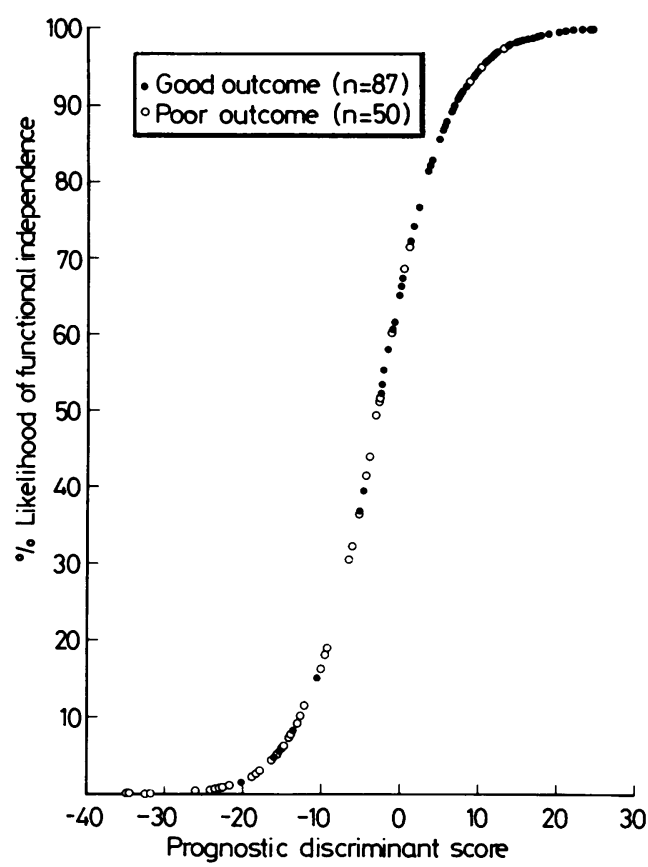

Fig A patient's total score from table 7 may be converted into a statement of his likely outcome with this figure. A score of $-2 \cdot 5=50 \%$ chance of recovery, $-15=5 \%$ and $+10=95 \%$.

24 hours there was a trend (not significant) for those with a good outcome to have lower pressures than those who became dependent or died. These data may have important implications concerning the acute treatment of blood pressure after stroke and are being further analysed.

The outcome categories used in this study were made deliberately simple. The object was to answer the clinician's question "What is the likelihood of this patient surviving to a state of functional independence?". Some authors have advocated the use of formal scales of disability such as the Barthel Index. ${ }^{4}$ However it has been shown that patients do not always undertake in the actual daily life, activities of which they have been judged capable. ${ }^{8}$ In this study the example has been taken of Marquardsen ${ }^{9}$ and others who also grouped their patients according to their overall functional status.

The correlation of the outcome assessment with the patients' ability to make simple transfers show that independence was strongly correlated with mobility (table 2). Other factors however were clearly important since some of the patients were relatively mobile and yet dependent.
This study confirms that in general the level of recovery after two months is a reasonable guide to the long term outlook after a stroke. ${ }^{10} \mathrm{~A}$ few patients will make substantial advances in their rehabilitation after this period and many continue to improve in ways which are difficult to measure objectively.

Discriminant function analysis has been used in other clinical situations to quantify diagnostic ${ }^{112}$ and prognostic judgements. ${ }^{13}$ Such analysis permits expression of the diagnosis or prognosis in terms of statistical probability rather as a vague clinical statement. $^{51314}$ An inherent limitation of this method is that the classification achieved will be most accurate in the group of patients from which the data were derived. For this reason care was taken to obtain data from a sample as representative of the general hospital population of stroke victims as possible.

An arbitrary interval of 24 hours from admission was selected before the patients were eligible for the study partly for practical reasons of study design. Furthermore, patients who are in mortal danger on admission with a stroke are usually easy to identify with evidence of large lesions, coma and pupillary or respiratory abnormalities. ${ }^{9}$ The selection of patients under the age of 76 years probably accounts for the preponderance of males in this sample, there being a higher proportion of females in the elderly stroke population. ${ }^{9}$

The scoring system described in this paper can be applied easily by any physician to his own stroke patients. Access to a computer is not necessary to score a patient; the most complex mathematics involved is the multiplication of the patient's age by $0 \cdot 4$. This product and the scores for each feature present (table 7) are then added or subtracted from the constant of +40 . This total can then be translated into an expression of the probable outcome by reference to the fig. As a rough guide, a score of -2.5 implies an even chance of recovery, scores of -15 and +10 suggest a $95 \%$ likelihood of a poor and good outcome respectively.

Although such complex statistical analysis as used here may seem alien to many clinicians, a similar process of sifting and weighting probably underlies many more intuitive judgements made on the basis of individual clinical experience. The purpose of this prognostic score is to make such clinical judgements more objective. Thus a patient may present with a total hemiplegia (score -12) with no other deficit (score +8$)$ but his recovery will depend somewhat on whether he is 55 years old (score $55 \times-0.4=$ -22 ) or 75 years (score $75 \times-0.4=-30$ ). In the latter case the patient's older age will have cancelled out the prognostic advantage in having an uncompli- 
cated hemiplegia.

The imperfections of this scoring system are illustrated by the patients represented in the figure by dots on the inappropriate part of the curve. These exceptions are a reminder that other factors, not assessed in this study, may affect patients' outcome after a stroke including the social and emotional consequences of their illness. ${ }^{15}$

The additional prognostic value of the CT scan evidence of the site and volume of the lesions causing stroke in this group of patients is being investigated. Nevertheless it appears that a reasonably accurate individual prognosis can be made by the simple clinical criteria used in this scoring system.

I thank all the physicians of Guy's Hospital who allowed me to study patients under their care; Dr RD Hoare who interpreted the CT scans; Mrs R Brown (Dept of Community Medicine, Guy's Hospital) who provided statistical and computing advice; the computing services of the Institute of Neurology and the Middlesex Hospital Medical School, where I did the computing; Dr MJG Harrison who reviewed the manuscript; and finally $\mathrm{Dr}$ RAC Hughes who provided continual support and encouragement throughout the study and advised on the preparation of the manuscript.

This research was supportd by a grant from the Special Trustees of Guy's Hospital.

\section{References}

' Prescott RJ, Garraway WM, Akhtar AJ. Predicting functional recovery following acute stroke using a standard clinical examination Stroke 1982;13:641-7.

${ }^{2}$ Marquardsen J. Natural history and prognosis of cerebrovascular disease. In: Ross Russell RW, ed. Vascu- lar Disease of the Central Nervous System London: Churchill Livingstone, 1983.

${ }^{3}$ Dyken ML. Natural history of ischaemic stroke. In: Harrison MJG and Dyken ML, eds. Cerebral Vascular Disease London: Butterworths, 1983.

${ }^{4}$ Wade DT, Skilbeck CE, Hewer RL. Predicting barthel ADL score at 6 months after an acute stroke. Arch Phys Med Rehabil 1983;64:24-8.

${ }^{5}$ Allen CMC. Clinical diagnosis of the acute stroke syndrome. $Q J$ Med 1983;52:515-23.

- Nie NH, Hull CH, Jenkins CG, Steinbrenner K, Bent DH. Statistical Package for the Social Sciences. New York: McGraw Hill, 1975.

${ }^{7}$ Armitage P. Statistical Methods in Medical Research Oxford: Blackwell, 1971.

${ }^{8}$ Sheikh K, Smith DS, Meade TW, Goldberg E, Brennan PJ, Kinsella G. Repeatability and validity of modified activities of daily living index in studies of chronic disability. International Rehabilitation Medicine 1970;1:51-8.

${ }^{9}$ Marquardsen J. The Natural History of Acute Cerebrovascular Disease: a Retrospective Study of 769 Patients. Copenhagen: Munksgaard, 1969.

${ }^{10}$ Skilbeck CE, Wade DT, Hewer RL, Wood VA. Recovery after stroke. J Neurol Neurosurg Psychiatry 1983;46:5-8.

" Fraser P, Healy M, Rose N, Watson L. Discriminant functions in the differential diagnosis of hypercalcaemia. Lancet 1971;i:1314-9.

12 Cohn PF, Gorlin R, Vokonas PS, Williams RA, Herman MV. A quantitative clinical index for the diagnosis of symptomatic coronary artery disease. $N$ Engl J Med 1972;286:901-7.

${ }^{13}$ Luria MH, Knoke JD, Wachs JS, Luria MA. Survival after recovery from acute myocardial infarction, two and five indices. Am J Med 1979;67:7-14.

${ }^{14}$ Dolgin SM, Schwartz JS, Kressel HY, et al. Identification of patients with cholesterol or pigment gallstones by discriminant function analysis of radiographic features. $N$ Engl J Med 1981;304:808-11.

${ }^{15}$ Holbrook M. Stroke: social and emotional outcome. $\boldsymbol{J} \boldsymbol{R}$ Coll Physicians (Lond) 1982;16:100-4. 